\title{
Developing an Automated Monitoring System for Cable Yarding Systems
}

\author{
Raimondo Gallo, Rien Visser, Fabrizio Mazzetto
}

\begin{abstract}
Cable yarders are often the preferred harvesting system when extracting trees on steep terrain. While the practice of cable logging is well established, productivity is dependent on many stand and terrain variables. Being able to continuously monitor a cable yarder operation would provide the opportunity not only to manage and improve the system, but also to study the effect on operations in different conditions.

This paper presents the results of an automated monitoring system that was developed and tested on a series of cable yarder operations. The system is based on the installation of a Geographical Navigation Satellite System (GNSS) onto the carriage, coupled with a data-logging unit and a data analysis program. The analysis program includes a set of algorithms able to transform the raw carriage movement data into detailed timing elements. Outputs include basic aspects such as average extraction distance, average inhaul and outhaul carriage speed, but is also able to distinguish number of cycles, cycle time, as well as break the cycles into its distinct elements of outhaul, hook, inhaul and unhook.

The system was tested in eight locations; four in thinning operations in Italy and four clear-cut operations in New Zealand, using three different rigging configuration of motorized slackpulling, motorized grapple and North Bend. At all locations, a manual time and motion study was completed for comparison to the data produced by the newly developed automated system. Results showed that the system was able to identify $98 \%$ of the 369 cycles measured. The 8 cycles not detected were directly attributed to the loss of GNSS signal at two Italian sites with tree cover. For the remaining 361 cycles, the difference in gross cycle time was less than $1 \%$ and the overall accuracy for the separate elements of the cycle was less than $3 \%$ when considered at the rigging system level. The study showed that the data analyses system developed can readily convert GNSS data of the carriage movement into information useful for monitoring and studying cable yarding operations.
\end{abstract}

Keywords: precision forestry, GNSS, cable logging, forest mechanization performance, operational monitoring

\section{Introduction}

Information Technology (IT) plays an important role in most modern industries. In the forest industry, this discipline has developed over the last ten years and is commonly referred to as »Precision Forestry«. Precision Forestry implies the use of IT for improving the performance and efficiency of the forest operations (Taylor et al. 2001), and forest management (Kovácsová and Antalová 2010). Its goal is to become a strategic tool for decision support systems (DSS) (Kovácsová and Antalová 2010, Lubello and Cavalli 2006, Taylor et al. 2002).
Since 2000, all the »new generation « forestry machines have been equipped with at least one on-board computer (OBC) equipped with different software for operational and management purposes (e.g., StanForD, MaxFleet) (Palander et al. 2013). These systems may be considered as a tool that allows the operator to monitor, manage, set and store all those parameters that enable the machine to work with high standards of efficiency (Laforest and Pulkki 2011, Veal et al. 2001). In addition, the collected information related to the characteristics of the processed trees can also be used to developed site-specific yield maps (Olivera and Visser 2016a). 
Currently, mainly in small forestry enterprises, the machinery IT tools are just used for monitoring specific parameters during the operations and not for management or logistic purposes. As such, the true capabilities of IT are not fully exploited to improve harvesting operations. One reason could be the necessity to perform a series of tasks, including downloading, organizing and interpreting the collected data in order to obtain usable information. A lack of time or IT skills might be the main obstacle in the advanced use of this capability.

Time study in forestry is usually done through the use of stopwatches (de Hoop and Dupré 2006), hand held computers (Holzleitner et al. 2011, Spinelli and Kofman 1995, Spinelli and Visser 2008, Wang et al. 2001) or by automated data collectors attached to computers and CAN-bus channels of forest machines (Nuutinen et al. 2010, Palander et al. 2013). Data-loggers that are capable of automatically identifying time elements and delays were developed and tested in the 1980s (Sauder 1981). A range of studies have used GNSS units for operational time detection (e.g. (Ackerman et al. 2016, Borz 2016, Cordero et al. 2006, Hejazian et al. 2013, Macrì et al. 2016, McDonald 1999, McDonald et al. 2001, McDonald and Fulton 2005, Nurek 2010, Strandgard and Mitchell 2015, Taylor et al. 2006, Veal et al. 2001). This methodology, sometimes synchronized with other sensors, can be used to track machines during felling and skidding operations (Grigolato et al. 2016, Spinelli et al. 2015), aerial harvesting with helicopter (Horcher and Visser 2011, Stampfer et al. 2002), and for tracking trucks for timber haulage (Devlin et al. 2008, Devlin and McDonnell 2009b, 2009a, Sikanen et al. 2005, Simwanda et al. 2011).

Some reports describe the use of GNSS devices for operational monitoring purposes in yarding activities for the analysis of productivity (Davis and Kellogg 2005, Nitami et al. 2011) or at early stage developments for automatic time studies (Gallo et al. 2018, Pierzchała et al. 2017). In general, the data collected during the operational monitoring by means of a GNSS device can be used to elaborate on machinery management information (Taylor et al. 2002).

For the potential of IT systems to be fully realized in the application of time studies, it is important to provide systems that are able to interpret and evaluate data autonomously. Veal et al. (2001) recognized the importance and necessity for the forestry sector of an »intelligent, automated system that will simultaneously acquire data on basic machine parameters, productivity, and general operating conditions «. In order to acquire operational time study information, a set of procedures are necessary to register the productivity and efficiency of a working system (Mundel and Danner 1994).

Cable logging is a complex harvesting systems typically characterized by a lower level of integrated IT systems, if compared to the Nordic based cut-tolength machines (using harvesters and forwarders), where the use of both on-board computer and GNSS are common (Olivera and Visser 2016b). As such, this project aimed to develop a set of interpretative procedures using readily available GNSS technology suitable for carrying out an autonomous time study. Therefore, the overall goal of the study was a first step for the development of a dedicated autonomous data capture and analytical procedure. Such a system could then be used for operational monitoring, or for time and motion studies of cable logging operations.

\section{Materials and Methods}

Studies were conducted in four yarder operation sites in Italy and four in New Zealand. At each site a GNSS unit was attached to the carriage to capture data on all carriage movements. Concurrent to the GNSS data collection, a continuous elemental time study was performed using a stopwatch and recording sheets. Gross cycle time was calculated by summing all four elements of the whole working cycle. The assessment of delays was not considered, as they are not part of the working cycle. The following time study elements were used:

$\Rightarrow$ Outhaul: begins when the carriage starts to move from the landing out to the loading site

$\Rightarrow$ Hook: begins when the carriage is stopped on the skyline

$\Rightarrow$ Inhaul: begins when the carriage starts to move back toward the landing

$\Rightarrow$ Unhook: begins when the logs are lowered from the carriage at the landing area

$\Rightarrow$ Delays: all delays (i.e. operational, mechanical, social).

Because of the scale of the operations, two people were sometimes required for data collection, one close to the choker-setting area and the other on the landing. The time-study crew communicate by walkie-talkie.

The following sections describe the GNSS technology used, the data interpretation process, as well as a the study sites.

\subsection{IT Equipment}

Several different GNSS units were used during this study: Asctech ${ }^{\circledR}$ MobileMapper 6; Garmin ${ }^{\circledR}$ GPSMAP 62s; Royaltek ${ }^{\circledR}$ RBT 3000 GNSS-datalogger; Eagle tree ${ }^{\circledR}$ OSD Pro Pkg. While the first three GNSS units were 
independent devices installed only for research purposes, the last one was a device already installed in the carriage to monitor its displacements. All of the units were similar, being relatively low-cost units with sub$10 \mathrm{~m}$ accuracy. While some consideration was given to the respective performance of the units given the difficult operating conditions, and although at times the signal was lost, they all performed well and no apparent differences were noticed. The use of different GNSS units did illustrate the robustness of the data interpretation system.

All units were set to record the satellites signals every 2 seconds. This threshold was chosen because it permits a good data interpretation and also because it offers a reasonable accuracy level, similar to what can be achieved with a manual time study using decimal stopwatches (Nuutinen et al. 2008). Data collected by Asctech ${ }^{\circledR}$ MobileMapper 6 and Royaltek ${ }^{\circledR}$ RBT 3000 were filtered at a PDOP threshold lower than 10 as this is considered a moderate value of precision (Liu et al. 2013). During this field tests, data were downloaded using Bluetooth or a cable connection directly to a computer at the end of each day.

All GNSS units and their components were mounted inside a high-density plastic box filled with foam to limit shock and damage. An external antenna with 2 meters of cable was used to improve the satellite signal detection. The box was attached to the carriage in a convenient and protected location using magnetic supports mounted on the box and, if required, with plastic ties. The external antenna was secured to the carriage with maximum exposure. This system was powered by internal batteries to avoid interference with the electronics of the machine and to ensure continued power supply in case of breakdowns.

\subsection{Data Interpretation Procedures}

The overall structure of the data intepretation procedure followed the main steps described in Mazzetto et al. (2019) and consisted of raw data collection, data processing and analyses to obtain final operative reports (Fig. 1). The approach was divided into three

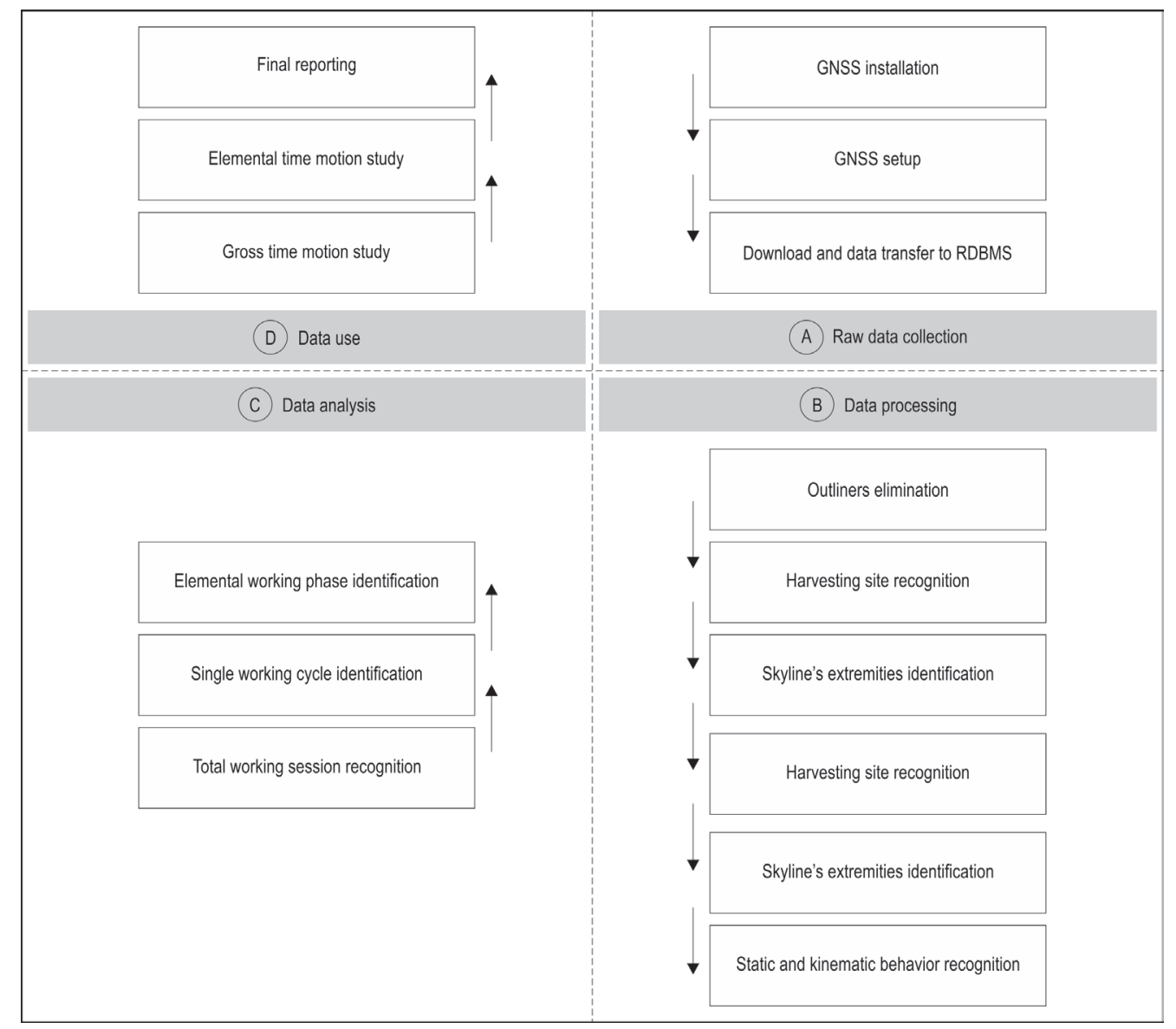

Fig. 1 Schematic representation of data process flowchart for ed system, showing how raw data is converted to obtain elemental time study information (after (Mazzetto et al. 2019)) 


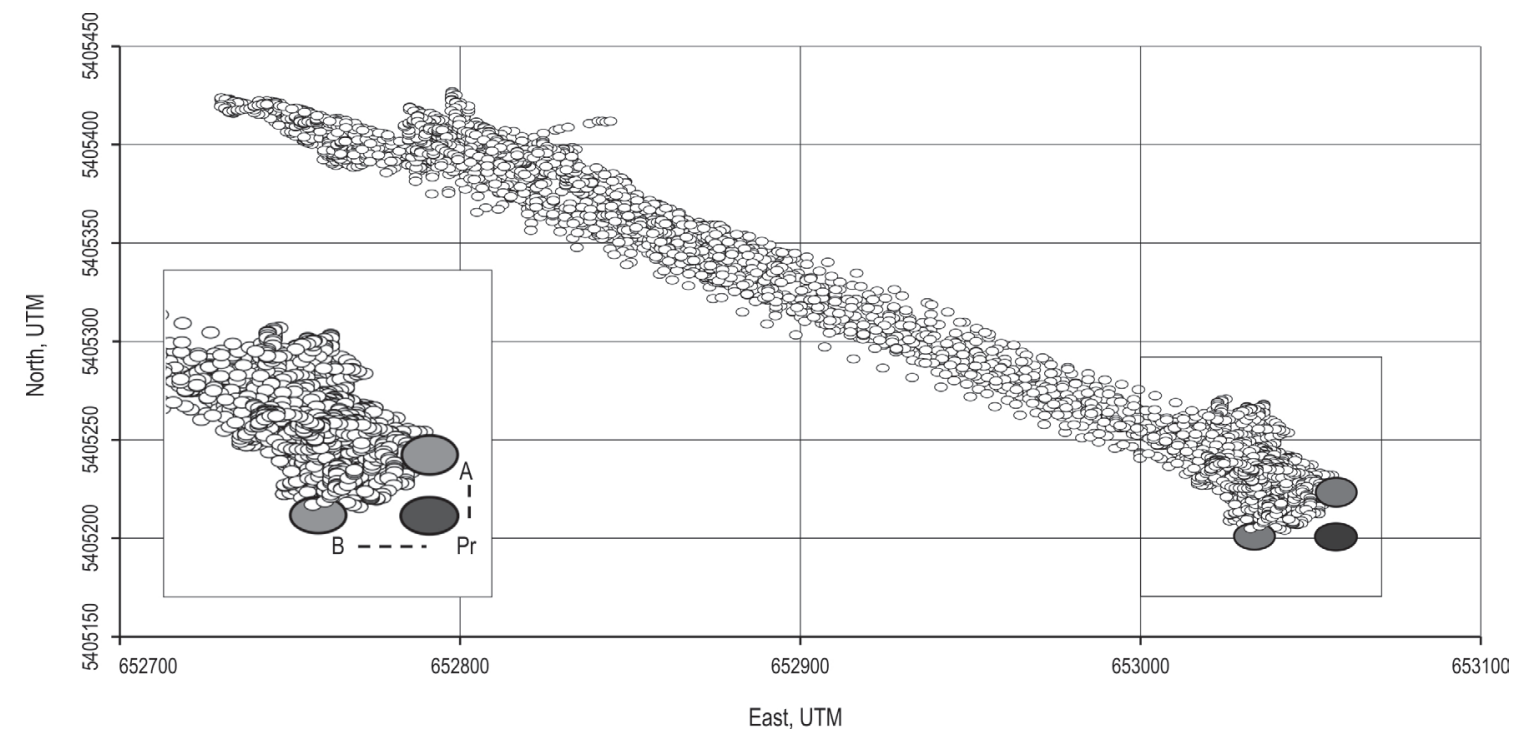

Fig. 2 Example of a distribution of GNSS points and identification of the yarder location (Pr) recognizing A and B as the extreme points of the cloud

areas, the box A to the tasks directly carried out by the user, boxes $\mathrm{B}$ and $\mathrm{C}$ refers to the sets of procedures performed by the Inference Engine and box D refers to the achieved outputs.

The procedure starts with the raw data collection through the on-board GNSS-datalogger. All the collected data is uploaded into a Relational Data Base Management System (RDBMS) for processing and analysis. Data download frequency depends on the transfer technology, which could be once a day in case of a manual downloading, or continuous in case of a GSM connection. In this study, the Inference Engine (IE) analyzed all the collected information. An IE is considered a software computer program able to transform, through a set of algorithms, raw data into intelligible management information, which can be used to make decisions or to perform controlling tasks (Mazzetto et al. 2012).

The raw GNSS data collected by the proposed system are $X, Y, Z$ coordinates and the time of each geospatial fixing. The code is written in Visual Basic for Application and runs in Microsoft Excel, and the raw data collected by the GNSS-datalogger is converted to .csv format.

For a cable yarding system, the carriage operation can be expected to be within a defined corridor along the skyline. The IE elaboration starts with the identification of the boundaries of the harvesting site. By way of example, the GNSS data (Northing and Easting) presented in Fig. 2 can be used to identify the harvest site by indicating the location of the skyline corridor. The vertexes of the boundary are identified consider- ing the maximum and minimum coordinates of the entire dataset. Therefore, the limits of the skyline, and in this case the location of the yarder, are approximately by the vertex $\operatorname{Pr}$ of points: $A\left(X_{\min } ; Y_{\min }\right)$ and $B$ $\left(X_{\min } ; Y_{\max }\right)$.

The IE continues with the computation of the distances between vertexes of the harvesting site and each detected point. The location of »landing area « (whereby the yarder location on the landing can be deduced at Pr) is recognized by analyzing the distribution of the frequency of these distances. The peak of the distance distribution identifies where the yarder is set up being as the centroid of the point cloud where the carriage is stopped to perform the unhooking operations. Considering the yarder location as starting point of the outhaul, the IE can determine the direction of travel.

Then the IE calculates the progressive time between two sequential time detections. Using these two parameters, it starts with the kinematic analysis of the carriage behavior during working operations. In this mode, it is possible to calculate the instantaneous travel speed of the carriage during outhaul and inhaul (Fig. 3). Analyzing the distribution of the speed frequency during travel, the IE is able to detect the representative speeds for both outhaul and inhaul (Fig. 4) as well as representative thresholds to define static or kinematic working phases.

The figure represents just some operative cycles performed during the logging operations, where all the hooking operations were performed at around $400 \mathrm{~m}$ from the landing area. The stops carried out at $100 \mathrm{~m}$ 


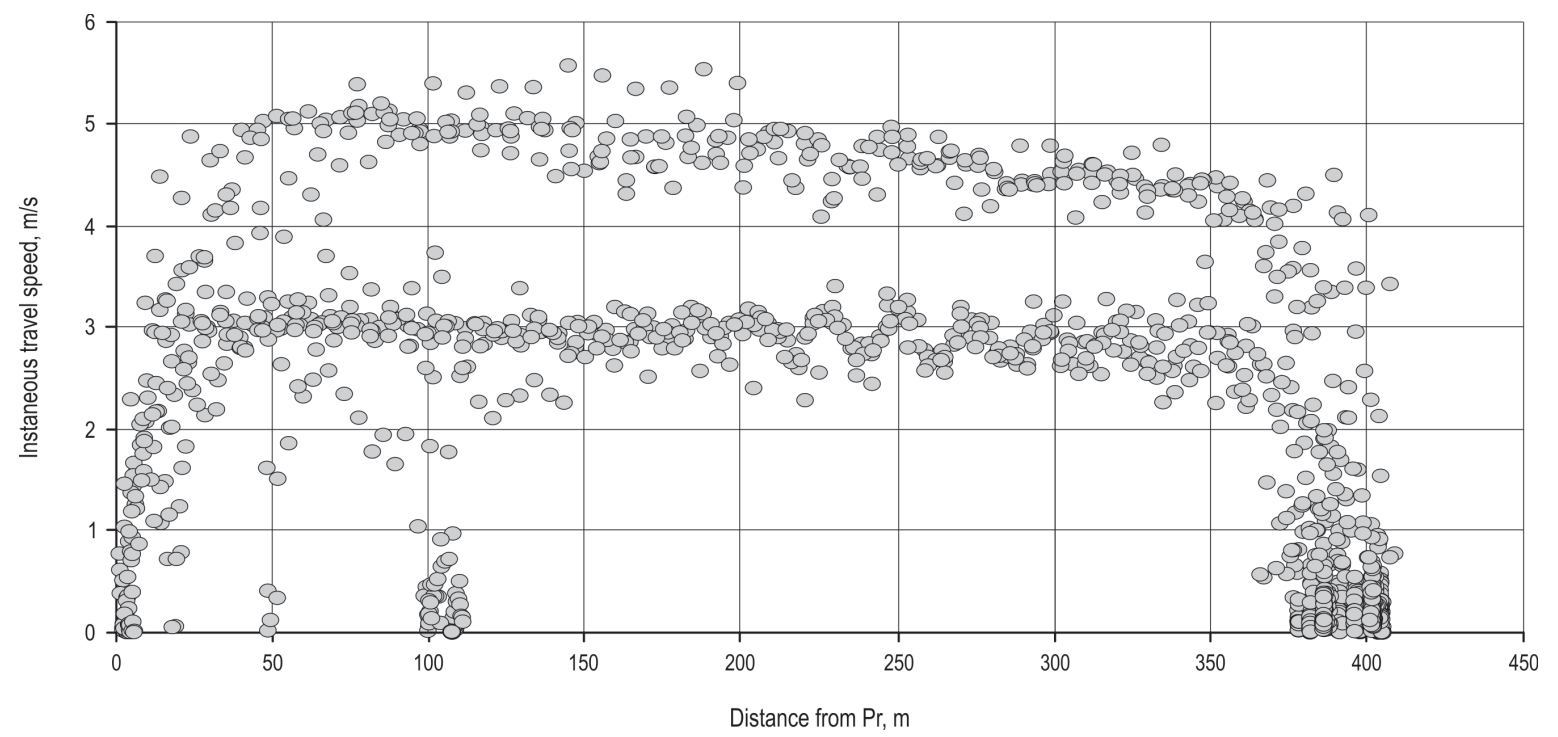

Fig. 3 Carriage speed in relation to distance from $\operatorname{Pr}$

distance from the landing area correspond to the place where all the accessory operations (e.g. refuelling, maintenance or parking of the carriage) were performed.

The IE proceeds with identifying the individual elements of the working cycle. As shown in Fig. 5, this is based around movement of the carriage relative to the closest point from the landing area; (1) movement of the carriage away from the landing area will be associated with outhaul, (2) a static period at a distance from the landing area will be »hook«, (3) carriage movement back towards the landing area will be $»$ inhaul «, and (4) a static period close to the inside of the landing area will be the »unhook « phase.

When analyzing a real dataset, the IE applies a filter on speed to have a more reliable dataset. Consequent$\mathrm{ly}$, the presence of noises in data acquisition due to the carriage movements during the lateral-in operations, little displacements along the line to find the best position for pulling or due to GNSS signal drift can be

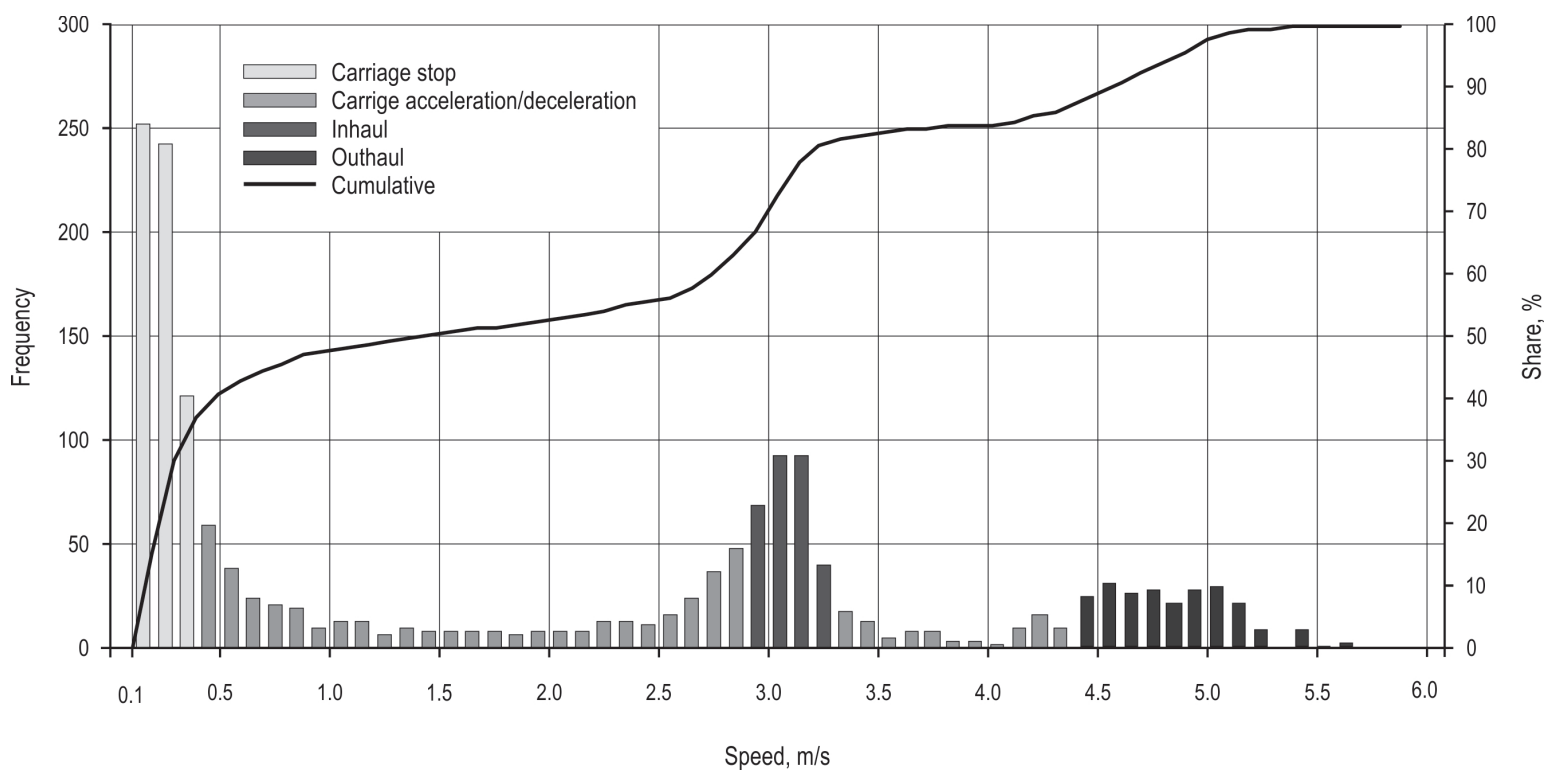

Fig. 4 Distribution of carriage speeds. Very low speed grouping around 0 is associated with hook and unhook tasks, whereas grouping around 4.8 and 3 are outhaul and inhaul, respectively, corresponding to carriage acceleration and deceleration 


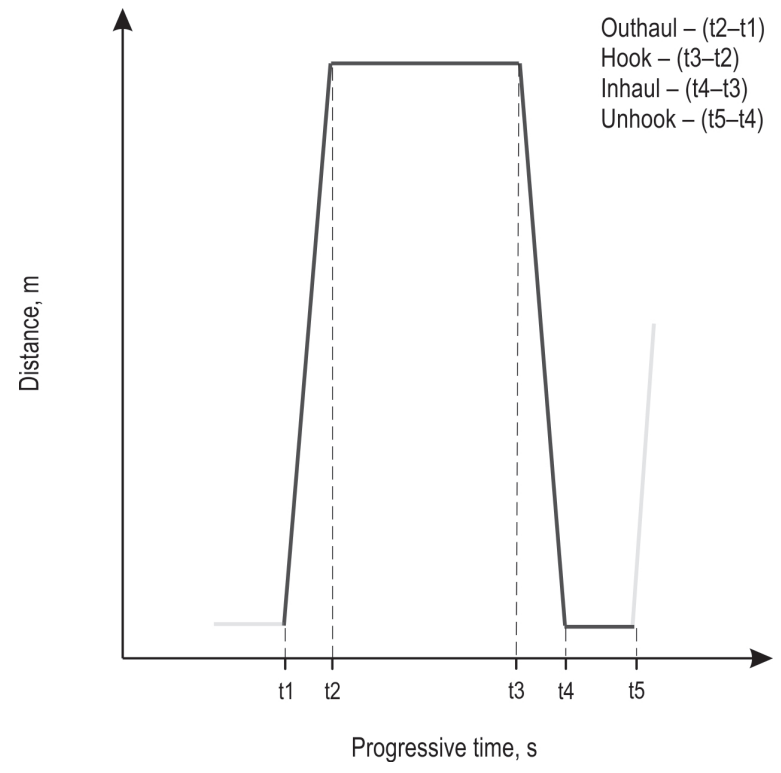

Fig. 5 Schematic of working cycle showing the distance of the carriage from the yarder as time progresses

removed. The IE elaborations proceed with the recognition of the elemental working phases. For these purposes the algorithms consider the identification of the landing area, its distance from the carriage, the advancement speed and at which distance from the landing the carriage stopped. As shown in Fig. 5, the IE considers a single cycle as the sequence of an outhaul, hook, inhaul and unhook operation. Therefore, through an iterative procedure, the system assesses if the above sequence of operations is respected and it performs their counting obtaining the total number of single cycles that make the working session. Subsequent to the working phase analysis and the identification of a single working cycle, the IE is able to recognize the points where one elementary phase finishes and the next one begins or where a delay has occurred. Considering the progressive time when an elemental phase changes, the effective time required to accomplish each phase is calculated through subtraction (Fig. 5). Summing the consecutive elemental phases, the total operative time for each cycle is also calculated. Hence, in this last analytical step, the effective time spent for each elementary operative phase, as well as for the gross time, can be automatically calculated by the system. For example, in Fig. 6 the outputs related to an actual automatic elemental time assessment are shown.

\subsection{Validation of Automatic Process of Time Study}

A validation of the automatic system was carried out to determine if the system works properly under different working systems. Field testing was carried out in four sites in Italy (Province of Bolzano) and six in New Zealand (Regions of Nelson, and Bay of Plenty). All operations studied were characterized by softwood forest, mainly spruce in Italy and radiata pine in New Zealand. In Italy, the harvesting operations were characterized by selective thinning with the carriage moving along a corridor that included forest canopy cover. The systems were mobile tower yarders rigged in a standing skyline configuration using a radio-controlled motorized slack pulling carriage (MSP).

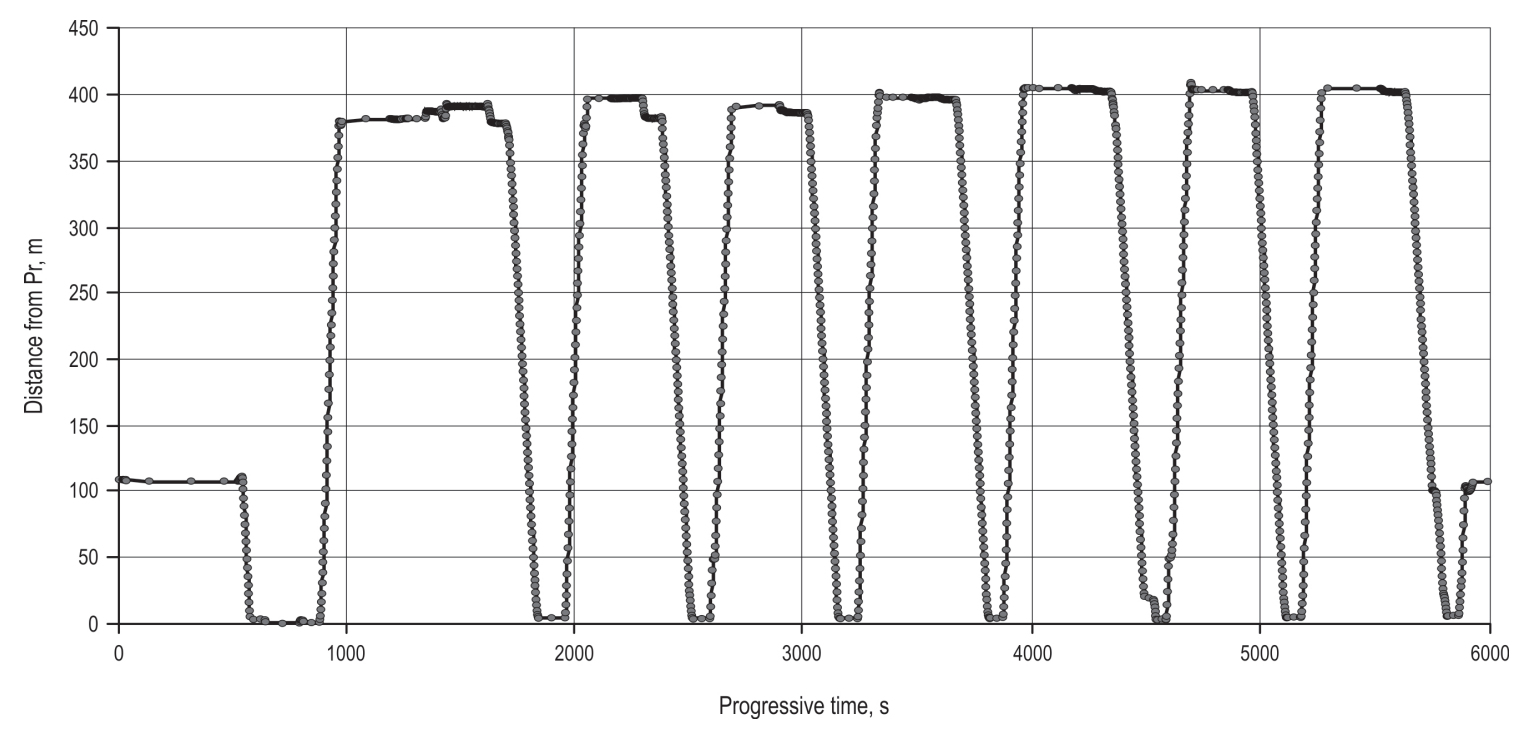

Fig. 6 Actual cycle analysis performed by the inference engine (IE). In this example, the monitoring starts at the distance of $100 \mathrm{~m}$ from the landing area, because that place corresponds to the recovery zone 
Table 1 Summary of study sites, equipment and GNSS modules used to carry out the automatic time study

\begin{tabular}{|c|c|c|c|c|c|}
\hline Study site & Region & Yarder & Yarding system & Configuration & GNSS unit \\
\hline ITA1 & Prov. BZ & \multirow{4}{*}{ Koller 507} & \multirow{4}{*}{ Standing Skyline } & \multirow{4}{*}{ Motorized slack pulling } & \multirow{4}{*}{$\begin{array}{c}\text { Asctech }{ }^{\circledR} \\
\text { MobileMapper } 6\end{array}$} \\
\hline ITA2 & Prov. BZ & & & & \\
\hline ITA3 & Prov. BZ & & & & \\
\hline ITA4 & Prov. BZ & & & & \\
\hline NZ1 & Nelson & Madill 171 & Live Skyline & Motorized grapple carriage & $\begin{array}{c}\text { Asctech }{ }^{\circledR} \\
\text { MobileMapper } 6 \\
\text { Eagle tree }{ }^{\circledR} \text { OSD Pro Pkg }\end{array}$ \\
\hline NZ2 & Nelson & Madill 071 & Live Skyline & North Bend & Garmin $®$ GPSMAP 62s \\
\hline NZ3 & Nelson & Madill 009 & Live Skyline & North Bend & Royaltek ${ }^{\circledR}$ RBT 3000 \\
\hline NZ4 & Bay of Plenty & Thunderbird TMY70 & Running Skyline & Butt rigging & Royaltek® RBT 3000 \\
\hline
\end{tabular}

The data collected in Italy in four separate sites are noted as ITA1 - ITA4 (Table 1). In New Zealand, all of the operations were clear-cut with the carriage fully exposed to the sky in all directions. The systems tested were (a) live skyline in a North Bend rigging configuration (NB), (b) running skyline using butt-rigging, as well as (c) motorized grappler carriage (MG). Tests were run at four different locations (NZ1 - NZ4). At the location NZ1, two different GNSS units were used on separate occasions.

Statistical analyses were carried out on the resulting datasets and consisted of a comparison of the IE calculated and manually recorded time study data. They included an evaluation of gross cycle time as well as of each elementary phase of the cycle. As all the observations are independent of each other, they were ordinal and as they did not have a normal distribution, the non-parametric test of Mann-Whitney $U(p<0.05)$ was performed using software SPSS 21.

\section{Results}

A total of about 41 hours of data was collected in Italy and 17.5 hours in New Zealand. During these time studies a total of 369 cycles were detected and analyzed by the manual time study, 226 cycles in Italy and 143 in New Zealand.

\subsection{Gross Time Study}

The IE was able to recognize 361 , or $98 \%$, of the cycles; so eight of the cycles (2.2\%) were not detected. Those eight cycles were missed at two Italian sites (ITA3 and ITA4) and could be traced back to an insuf- ficient number of satellites available during the GNSS data collection, as confirmed by Global Position System (GPS) data almanac. This was an overall error of $15.6 \%$ and $4.3 \%$ for those two sites, respectively. For all other six sites, there was no difference between cycle numbers predicted using the IE systems and those recorded using the manual time and motion study technique (Table 2). Taken as a whole, the manual time study had an average cycle time of $9.37 \mathrm{~min}$, whereas the IE calculated it to be $9.38 \mathrm{~min}$, so overall very accurate.

Table 2 Summary of gross time of cycles for each dataset. The acronym A_TS and M_TS refer to automatic and manual time study, respectively. MSP denotes Motorized Slack-pulling, MG is a gravity carriage, and N.B. is a North-Bend configuration

\begin{tabular}{|c|c|c|c|c|c|}
\hline \multirow{2}{*}{ Data-set } & \multirow{2}{*}{ Yarding system } & \multicolumn{2}{|c|}{ Cycles, $n$} & \multicolumn{2}{c|}{ Difference } \\
\cline { 3 - 6 } & & A_TS & M_TS & $\#$ & $\%$ \\
\hline ITA1 & MSP & 67 & 67 & - & 0 \\
\hline ITA2 & MSP & 59 & 59 & - & 0 \\
\hline ITA3 & MSP & 27 & 32 & 5 & 15.6 \\
\hline ITA4 & MSP & 67 & 70 & 3 & 4.3 \\
\hline NZ1 & MG & 64 & 64 & - & 0 \\
\hline NZ2 & N.B. & 15 & 15 & - & 0 \\
\hline NZ3 & N.B. & 23 & 23 & - & 0 \\
\hline NZ4 & N.B. & 39 & 39 & - & 0 \\
\hline & Total & 361 & 369 & 8 & 2.2 \\
\hline
\end{tabular}




\subsection{Elemental Time Study}

The 8 cycles not detected by the IE were deleted from the dataset for further analysis as there is no equivalent data to compare them with the manually recorded data. The elemental time study data was available for 361 cycles, broken down into four distinct phases: outhaul, hook, inhaul, and unhook. The IE was able to recognize $97.6 \%\left(N_{\text {tot }}=1476\right)$ of the elemental operative phases carried out. Only three elemental phases were not recognized: two in Italy and one in
New Zealand. Possible reasons included low number of satellites or poor distribution in the sky (Holden et al. 2001, Naesset et al. 2000, Simwanda et al. 2011), or partial coverage by the forest canopy.

The analysis of the elemental results obtained has been done combining the data-sets and distinguishing the different elemental working phases (Table 3). The differences recorded between the IE and manual time study show that they are not significant (at the 95\% probability level). The results show values lower than

Table 3 Statistics of elemental time study and total cycle recorded during cable logging yarding cycles. The acronym A_TS and M_TS refers to automatic and manual time study, respectively

\begin{tabular}{|l|c|c|c|c|c|c|c|c|}
\hline \multirow{2}{*}{} & \multicolumn{2}{|c|}{ Average, min } & \multicolumn{2}{c|}{ St. dev, min } & \multicolumn{2}{c|}{ Differences } & \multirow{2}{*}{$R^{2}$} & \multirow{2}{*}{$p$-value } \\
\cline { 2 - 9 } & A_TS & M_TS & A_TS & M_TS & $\min$ & $\%$ & & \\
\hline Outhaul & 1.39 & 1.35 & 1.22 & 1.21 & -0.04 & -3.0 & 0.91 & 0.38 \\
\hline Hook & 4.08 & 4.19 & 4.55 & 4.60 & 0.11 & 2.6 & 0.98 & 0.46 \\
\hline Inhaul & 2.27 & 2.21 & 1.46 & 1.44 & -0.06 & -2.7 & 0.88 & 0.41 \\
\hline Unhook & 1.63 & 1.62 & 3.91 & 3.89 & -0.01 & -0.6 & 0.99 & 0.73 \\
\hline Total cycle & 9.37 & 9.37 & 7.10 & 7.09 & 0.00 & 0.0 & 0.99 & 0.95 \\
\hline
\end{tabular}

Table 4 Statistics of elemental time study and total cycle recorded during cable logging yarding considering the logging system applied. Differences refer to the average values of the time motion study. The acronym A_TS and M_TS refers to automatic and manual time study, respectively. The asterisk means a statistical difference between time study methods

\begin{tabular}{|c|c|c|c|c|c|c|c|c|c|}
\hline \multirow{2}{*}{\multicolumn{2}{|c|}{ Logging systems }} & \multicolumn{2}{|c|}{ Average, min } & \multicolumn{2}{|c|}{ St. dev., min } & \multicolumn{2}{|c|}{ Differences } & \multirow{3}{*}{$\begin{array}{c}R^{2} \\
0.91\end{array}$} & \multirow{3}{*}{$\begin{array}{c}p \text {-value } \\
0.99\end{array}$} \\
\hline & & \multirow{2}{*}{$\frac{\text { A_TS }_{-}}{1.66}$} & \multirow{2}{*}{$\frac{M_{-} \text {TS }}{1.65}$} & \multirow{2}{*}{$\frac{\text { A_TS }_{-}}{1.01}$} & \multirow{2}{*}{$\frac{\text { M_TS }}{0.99}$} & \multirow{2}{*}{$\begin{array}{c}\text { min } \\
-0.01\end{array}$} & \multirow{2}{*}{$\begin{array}{c}\% \\
-0.6\end{array}$} & & \\
\hline \multirow{5}{*}{$\begin{array}{l}\underset{N}{ } \\
\| \\
\Sigma \\
\Sigma \\
\sum \\
\sum\end{array}$} & Outhaul & & & & & & & & \\
\hline & Hook & 4.8 & 4.93 & 3.48 & 3.59 & 0.13 & 2.6 & 0.98 & 0.53 \\
\hline & Inhaul & 2.72 & 2.56 & 1.40 & 1.38 & -0.16 & -6.3 & 0.93 & 0.22 \\
\hline & Unhook & 1.46 & 1.47 & 2.77 & 2.68 & 0.01 & 0.7 & 0.99 & 0.58 \\
\hline & Total Cycle & 10.64 & 10.61 & 5.39 & 5.40 & -0.03 & -0.3 & 0.99 & 0.91 \\
\hline \multirow{5}{*}{ 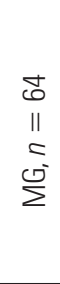 } & Outhaul & 0.48 & 0.56 & 0.28 & 0.43 & 0.08 & 14.3 & 0.49 & 0.11 \\
\hline & Hook & 0.83 & 0.85 & 0.43 & 0.38 & 0.02 & 2.4 & 0.83 & 0.50 \\
\hline & Inhaul & 1.36 & 1.31 & 0.91 & 0.95 & -0.05 & -3.8 & 0.96 & 0.39 \\
\hline & Unhook & 0.47 & 0.44 & 0.13 & 0.15 & -0.03 & -6.8 & 0.49 & 0.33 \\
\hline & Total Cycle & 3.13 & 3.17 & 1.01 & 1.06 & 0.04 & 1.3 & 0.93 & 0.91 \\
\hline \multirow{5}{*}{ 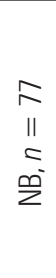 } & Outhaul & 1.38 & 1.12 & 1.74 & 1.74 & -0.26 & -23.2 & 0.34 & $0.001^{*}$ \\
\hline & Hook & 4.71 & 4.84 & 7.15 & 7.1 & 0.13 & 2.7 & 0.99 & 0.45 \\
\hline & Inhaul & 1.76 & 1.94 & 1.48 & 1.57 & 0.18 & 9.3 & 0.71 & 0.47 \\
\hline & Unhook & 3.07 & 3.03 & 6.79 & 6.82 & -0.04 & -1.3 & 0.99 & 0.83 \\
\hline & Total Cycle & 10.93 & 10.94 & 10.6 & 10.56 & 0.01 & 0.1 & 0.99 & 0.94 \\
\hline
\end{tabular}




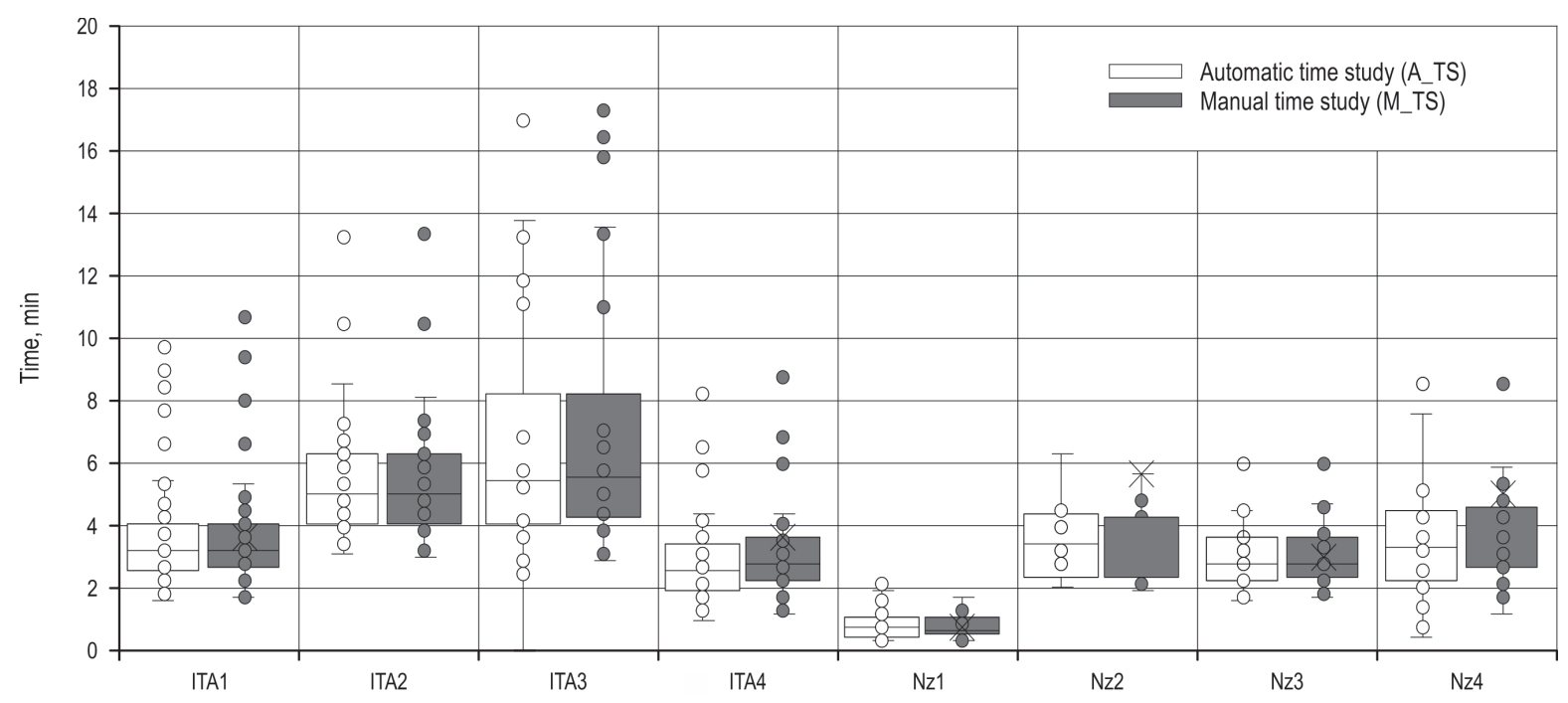

Fig. 7 Boxplot of four elemental working phases recorded by automatic (A_TS) and manual (M_TS) time study

those reported in literature (McDonald and Fulton 2005, Taylor et al. 2001), but greater if compared with those recorded for the gross time study.

The average differences recorded are $0.04 \mathrm{~min}$, $0.11 \mathrm{~min}, 0.06 \mathrm{~min}, 0.01 \mathrm{~min}$ and $0.01 \mathrm{~min}$, respectively, for outhaul, hook, inhaul, unhook and total cycle. These discrepancies might be due to the performance of the GNSS units used, or to a lack of geo-referenced detection as consequence of a loss or acquisition of GPS satellite signals, which involves the recalculation of the position that can lead to errors (Holden et al. 2001, Naesset et al. 2000, Simwanda et al. 2011).

A more detailed analysis is possible by grouping the studies together with regard to rigging system used (Table 4). This helps highlight where some of the larger differences occurred, as indicated by the $R^{2}$ values. For example, the outhaul and unhook elements of the grapple carriage showed a poor correlation (both $R^{2}=0.49$ ). This can partly be explained by the fact that delineation between the elements is not clear, with the carriage continuing to move towards a stem when »hooked" (grappled). Also the turn is typically released onto the landing in a fluid movement without a distinct stop. The other low correlation value is the North Bend outhaul. In this case, the GNSS was mounted on the fallblock because there was not enough place on the riderblock (»carriage «). Therefore, all the relative movements of the fall-block, such as dropping the skyline while the carriage was still moving towards the breaking out area or the landing, caused uncertainties in the distinguishing the switch between outhaul and hook.

To show the similarity between the manually recorded time study and the IE calculated results, Fig. 7 features a boxplot of the Hook data. The patterns in- cluding the average, standard deviation and outlier data, are almost identical and should give confidence in using the IE for future time study applications without the need for manual assessment.

\section{Discussion}

The study has shown that the hardware system is very flexible and can be installed quickly under a range of operational conditions. With the GNSS unit installed on the carriage of a standing skyline, excellent accuracy is achieved for all the carriage stops and starts. For the live skyline systems, the placement of the receiver unit is important because the carriage is brought to the ground each cycle and an external mounted GNSS unit can easily be knocked off. Live skyline operations can also be more dynamic without clear distinction between elemental phases, and therefore the IE will require some improvement to better assess the dynamic aspects.

During the monitoring operations, the system proved to be reliable in both thinning operation and clear-cuts, even if some interferences from the forest canopy were detected. To increase the acquisition accuracy of the system and to reduce the risk of missing signal, it can be recommended to test data acquisition with devices able to acquire data from multiple constellations, such as GPS, GLObal NAvigation Satellite System (GLONASS) (Kovácsová and Antalová 2010, Naesset et al. 2000, Valbuena et al. 2010) or to use the newest BeiDou navigation satellite system (BDS) and Galileo navigation system. Moreover, as suggested in literature, increasing the value of the PDOP filter to 20 
may provide a better solution for dynamic data acquisition with GNSS devices (Holden et al. 2002).

In the literature, only two reports were found that aim to develop a system able to collect operational data in cable yarding operation (Gallo et al. 2013, Pierzchała et al. 2017). Gallo et al. (2013) proposed a similar application, where the precision of the GNSS acquisitions was affected by errors due to multipath phenomena caused by poor positioning of the GNSS antenna. During their test, the antenna was attached to the lateral side of the carriage and the large metal surface of the carriage caused GNSS signal multipath effect. To avoid this issue, in the current tests the antenna was always placed on the top of the carriages or pulleys in order to ensure the best sky visibility. Consequently, the IE elaborations resulted in greater accuracy for both the elemental and gross time studies. Only the identification of the outhaul in the North Bend configuration recorded differences in minutes higher than those collected by Gallo et al. (2013).

Pierzchala et al. (2017) proposed a system where an Inertial Measurement Unit (IMU), a GNSS, 2 cameras, a system for Wi-Fi data transmission, a microcomputer and an external battery are connected together and installed on a carriage. With the fusion of those sensors, the Authors obtained good results in the recognition of elemental operations with some uncertainties in the identification of the choking, lateral-in and outhaul phases. They also showed that the use of Wi-Fi technology can be a practical solution to ensure a real-time data transfer for operational monitoring purposes. Nevertheless, the trial setup and the number of sensors required by this innovative system rise some doubt on its installation on long yarding lines and on different carriages or rigging configurations.

For very long reaches where WiFi signal may be lost, it is possible to install repeaters on intermediate supports. This solution requires more time for mounting and dismounting as well as more maintenance (repeater power supply, controls of the cable connections). A large number of sensors requires considerable time to be installed on a carriage. Moreover, the higher the number of sensors, the higher the risk of damage caused by chokers or branches.

Considering other research, the application described here may be easily implemented in systems for the purpose of hazard monitoring during yarding operations (Wempe and Keefe 2017). If implemented in a real-time monitoring system, the data collected by this application could be used not only to carry out an automatic time study, but also to define mobile virtual geofences to avoid any kind of injuries for the operators on the landing or breaking out zones in case of proximity to the carriage (Zimbelman et al. 2017).

The solution described in this paper could be synchronized with other solutions, such as skyline tension monitoring in order to automatically identify the operative phase during which a shock event occurs (Spinelli et al. 2017); or to automatically assess important parameters for yarding productivity and cost assessment (e.g. yarding distances, number of cycles and gross or elemental time measurements) that nowadays are manually measured (Hoffmann et al. 2015, Lee et al. 2018, Proto et al. 2016, Spinelli et al. 2010).

\section{Conclusions}

This paper reports the results of procedures implemented to carry out an automatic operational monitoring system for cable logging operations. The approach is based on the development of dedicated data analysis procedures, called »inference engine«, able to carry out an automatic data evaluation. These procedures are a set of codes able to analyze the yarding cycles in detail in order to obtain gross time as well as time spent for each elemental phase.

This study has demonstrated that the proposed approach has good capabilities and reliability in automatically recognizing the total number of cycles $(98 \%)$. Tested at eight different sites, the total gross time difference with manually collected data was negligible. The elemental time study difference was 3\%, $2.6 \%$, $2.7 \%$ and $0.6 \%$, respectively, for outhaul, hook, inhaul and unhook operative phase. These results were obtained using GNSS units with different technical specifications, therefore the characteristics of the equipment used for data collection did not affect data analysis and interpretation.

The study did show that yarding and rigging configuration can affect results. The fall block used on North Bend, and the live skyline used for the Grapple Carriage both had low correlations for some of the elemental phases. For improved accuracy in North Bend, the GNSS should be installed on the carriage or pulley that runs on the skyline (rider block), but also the inference engine should be refined in order to better recognize the phase change (e.g. the break point) between unhook and outhaul. An important characteristic of the system is easy installation that does not require any mechanical or electronic interventions on the original machine, as well as the automatic or semiautomatic data download and data evaluation for activity reporting.

While the system is excellent for analyzing time elements of the operations, it is recognized that, to 
measure the full performance of a crew or machine, the system must be integrated with an analysis of turn volume to establish comparable productivity rates.

\section{Acknowledgments}

The authors wish to thank Dr. Werner Noggler and the Azienda Foreste e Demanio of the Autonomous Province of Bolzano for the collaboration and support during the studies in Italy, as well as the support of the New Zealander harvesting crews, and name Hunter Harrill (Researcher, University of Canterbury, Christchurch) for coordinating the South Island visits, and Hamish Macpherson (Harvest Manager, PF Olsen, Rotorua) for the North Island.

\section{References}

Ackerman, P., Pulkki, R., Odhiambo, B., 2016: Comparison of Cable Skidding Productivity and Cost : Pre-Choking Mainline Versus Tagline Systems. Croat. J. For. Eng. 37(2): 261-268.

Borz, S.A., 2016: Turning a winch skidder into a self-data collection machine using external sensors: A methodological concept. Bull. Transilv. Univ. Brasov, Ser. II For. Wood Ind. Agric. Food Eng. 9(2): 1-6.

Cordero, R., Mardones, O., Marticorena, M., 2006: Evaluation of forestry machinery performance in harvesting operation using GPS technology. Precicion For. Plant. SemiNatural Nat. For. 163-173.

Davis, C., Kellogg, L., 2005: Measuring machine productivity with the MultiDat datalogger: a demonstration on three forest machines. In Council on Forest Engineering Conference Proceedings, $10 \mathrm{p}$.

De Hoop, C.F., Dupré, R., 2006: Using GPS to document skidder motions - a comparison with manual data collection. Work. Glob. - Shar. For. Eng. Challenges Technol. Around World: 393-402.

Devlin, G., McDonnell, K., 2009a: Assessing real time GPS asset tracking for timber haulage. Open Transp. J. 3: 78-86. https://doi.org/10.2174/1874447800903010078

Devlin, G., McDonnell, K., 2009b: Performance accuracy of real-time GPS asset tracking systems for timber haulage trucks travelling on both internal forest road and public road networks. Int. J. For. Eng. 20(1): 45-49. https://doi.org/10.10 80/14942119.2009.10702575

Devlin, G., McDonnell, K., Ward, S., 2008: Timber haulage routing in Ireland: an analysis using GIS and GPS. J. Transp. Geogr. 16(1): 63-72. https://doi.org/10.1016/j.jtrangeo.2007.01.008

Gallo, R., Carabin, G., Vidoni, R., Sacco, P., Mazzetto, F., 2018: Solutions for the automation of operational monitoring activities for agricultural and forestry tasks. Bodenkultur 69(3): 131-140. https://doi.org/10.2478/boku-2018-0012
Gallo, R., Grigolato, S., Cavalli, R., Mazzetto, F., 2013: GNSSbased operational monitoring devices for forest logging operation chains. J. Agric. Eng. 44(s2): . https://doi.org/10.4081/ jae.2013.s2.e27

Grigolato, S., Panizza, S., Pellegrini, M., Ackerman, P., Cavalli, R., 2016: Light-lift helicopter logging operations in the Italian Alps: a preliminary study based on GNSS and a video camera system. Forest Sci. Technol. 12(2): 88-97. https://doi.org/10.1080/21580103.2015.1075436

Hejazian, M., Hosseini, S., Lotfalian, M., Ahmadikoolaei, P., 2013: Possibility of global positioning system (GPS) application for time studies in forest machinery. Eur. J. Exp. Biol. 3(4): 93-98.

Hoffmann, S., Jaeger, D., Schoenherr, S., Talbot, B., 2015: Challenges in mechanization efforts of small diameter eucalyptus harvesting operations with a low capacity running skyline yarder in southern China. Forests 6(9): 2959-2981. https://doi.org/10.3390/f6092959

Holden, N.M., Delgado, F., Owende, P., Ward, S., 2002: Performance of a differential GPS in dynamic mode under sitka spruce canopies. Int. J. For. Eng. 13(1): 33-40. https://doi.org /10.1080/14942119.2002.10702455

Holden, N.M., Martin, A.A., Owende, P., Ward, S., 2001: A method for relating GPS performance to forest canopy. Int. J. For. Eng. 12(2): 51-56. https://doi.org/10.1080/14942119.20 01.10702446

Holzleitner, F., Kanzian, C., Stampfer, K., 2011: Analysing time and fuel consumption in road transport of round wood with an onboard fleet manager. Eur. J. For. Res. 130(2): 293301. https://doi.org/10.1007/s10342-010-0431-y

Horcher, A., Visser, R., 2011: Using On-Board GPS to Identify Training Needs of Helicopter Pilots. Croat. J. For. Eng. 32(2): 481-488.

Kovácsová, P., Antalová, M., 2010: Precision Forestry - Definition and technologies. Šumarski List 134(11): 603-611.

Laforest, S., Pulkki, R., 2011: Case study on integrating onboard computers in northern Ontario's forest supply chains. $34^{\text {th }}$ Council on Forest Engineering, June 12-15 Quebec City, $13 \mathrm{p}$.

Lee, E., Im, S., Han, S.K., 2018: Productivity and cost of a small-scale cable yarder in an uphill and downhill area: a case study in South Korea. Forest Sci. Technol. 14(1): 16-22. https://doi.org/10.1080/21580103.2017.1409662

Liu, X., Jiao, W., Bai, Y., Fan, J., 2013: Global coverage performance analysis based on 4 BeiDou MEO satellites. In China satellite navigation conference (CSNC). Proceedings Springer, Berlin, Heidelberg, 319-329 p.

Lubello, D., Cavalli, R., 2006: Ambiti Applicativi della Precision Forestry. Sherwood - For. Ed Alberi Oggi 125: 11-16.

Macrì, G., Zimbalatti, G., Russo, D., Proto, A.R., 2016: Measuring the mobility parameters of tree-length forwarding systems using GPS technology in the Southern Italy forestry. Agron. Res. 14(3): 836-845. 
Mazzetto, F., Gallo, R., Riedl, M., Sacco, P., 2019: Proposal of an ontological approach to design and analyse farm information systems to support Precision Agriculture techniques. Proposal of an ontological approach to design and analyse farm information systems to support Precision Agriculture techniques. IOP Conf. Ser. Earth Environ. Sci. 275: 012008. https://doi.org/10.1088/1755-1315/275/1/012008

Mazzetto, F., Sacco, P., Calcante, A., 2012: Algorithms for the interpretation of continuous measurement of the slurry level in storage tanks. J. Agric. Eng. 43(1): e6. https://doi. org/10.4081/jae.2012.e6

McDonald, T.P., 1999: Time study of harvesting equipment using GPS-derived positional data. Foresty Engineering for Tomorrow, GIS Technical Papers, Edinburgh University, Edinburgh, Scotland, 8 p.

McDonald, T.P., Fulton, J.P., 2005: Automated time study of skidders using global positioning system data. Comput. Electron. Agric. 48(1): 19-37. https://doi.org/10.1016/j.compag.2005.01.004

McDonald, T.P., Rummer, B., Taylor, S.E., 2001: Automating time study of feller-bunchers. In Proceedings of the Canadian Woodlands Forum's $81^{\text {st }}$ Annual Meeting and Council on Forest Engineering's $23^{\text {rd }}$ Annual Meeting-Technologies for New Millennium Forestry, Kelowna, BC.

Mundel, M., Danner, D., 1994: Motion and time study - improving productivity (U. S. River (ed.)) Prentice Hall.

Naesset, E., Bjerke, T., Bvstedal, O., Ryan, L., 2000: Contributions of differential GPS and GLONASS observations to point accuracy under forest canopies. Photogramm. Eng. Remote Sens. 66(4): 403-407.

Nitami, T., Suk, S., Kataoka, A., Mitsuyama, T., 2011: Tower Yarder Operation in Japan and the Performance Analysis by GPS based system. Push. Boundaries with Res. Innov. For. Eng. FORMEC 2011, Proc. $44^{\text {th }}$ Int. Symp. For. Mech. 1-6.

Nurek, T., 2010: Utilization of satellite system in monitoring of machines in forest operations. Ann. Warsaw Univ. Life Sci. Agric. For. Eng. 56: 89-94.

Nuutinen, Y., Vaatainen, K., Asikainen, A., Prinz, R., Heinonen, J., 2010: Operational efficiency and damage to sawlogs by feed rollers of the harvester head. Silva Fenn. 44(1): 165. https://doi.org/10.14214/sf.165

Nuutinen, Y., Väätäinen, K., Heinonen, J., Asikainen, A., Röser, D., 2008: The Accuracy of Manually Recorded Time Study Data for Harvester Operation Shown via Simulator Screen. Silva Fenn. 42(1): 264. https://doi.org/10.14214/sf.264

Olivera, A., Visser, R., 2016a: Development of forest-yield maps generated from Global Navigation Satellite System (GNSS)-enabled harvester StanForD files: preliminary concepts. New Zeal. J. For. Sci. 46: 3. https://doi.org/10.1186/ s40490-016-0059-x

Palander, T., Nuutinen, Y., Kariniemi, A., Vaatainen, K., 2013: Automatic time study method for recording work phase times of timber harvesting. For. Sci. 59(4): 472-483. https:// doi.org/10.5849/forsci.12-009
Pierzchała, M., Kvaal, K., Stampfer, K., Talbot, B., 2017: Automatic recognition of work phases in cable yarding supported by sensor fusion. Int. J. For. Eng. 29(1): 12-20. https:// doi.org/10.1080/14942119.2017.1373502

Proto, A.R., Skoupy, A., Macri, G., Zimbalatti, G., 2016: Time consumption and productivity of a medium size mobile tower yarder in downhill and uphill configurations: a case study in Czech Republic. J. Agric. Eng. 47(4): 216-221. https:// doi.org/10.4081/jae.2016.551

Sauder, B.J., 1981: Automated identification of time-element and delay information using the Data Logger system. Fifth Northwest Skyline Logging Symposium, proceedings. University of Washington College of Forest Resources, 43: 116127.

Sikanen, L., Asikainen, A., Lehikoinen, M., 2005: Transport control of forest fuels by fleet manager, mobile terminals and GPS. Biomass and Bioenergy 28(2): 183-191. https://doi. org/10.1016/j.biombioe.2004.08.011

Simwanda, M., Wing, M., Sessions, J., 2011: Evaluating global position system accuracy for forest biomass transportation tracking within varying forest canopy. West. J. Appl. For. 26(4): 165-173. https://doi.org/10.1093/wjaf/26.4.165

Spinelli, R., Kofman, P., 1995: Cantieri agricoli e forestali, informatizzazione dei rilievi. Macch. e Mot. Agric. 11: 33-35.

Spinelli, R., Magagnotti, N., Lombardini, C., 2010: Performance, capability and costs of small-scale cable yarding technology. Small-Scale For. 9(1): 123-135. https://doi.org/10.1007/ s11842-009-9106-2

Spinelli, R., Magagnotti, N., Pari, L., De Francesco, F., 2015: A comparison of tractor-trailer units and high-speed forwarders used in Alpine forestry. Scand. J. For. Res. 30(5): 470-477. https://doi.org/10.1080/02827581.2015.1012113

Spinelli, R., Marchi, E., Visser, R., Harrill, H., Gallo, R., Cambi, M., Neri, F., Lombardini, C., Magagnotti, N., 2017: Skyline tension, shock loading, payload and performance for a European cable yarder using two different carriage types. Eur. J. For. Res. 136(1): 161-170. https://doi.org/10.1007/s10342016-1016-1

Spinelli, R., Visser, R., 2008: Analyzing and estimating delays in harvester operations. Int. J. For. Eng. 19(1): 36-41. https:// doi.org/10.1080/14942119.2008.10702558

Stampfer, K., Gridling, H., Visser, R., 2002: Analyses of Parameters Affecting Helicopter Timber Extraction. Int. J. For. Eng. 13(2): 61-68. https://doi.org/10.1080/14942119.2002.1070 2463

Strandgard, M., Mitchell, R., 2015: Automated time study of forwarders using GPS and a vibration sensor. Croat. J. For. Eng. 36(2): 175-184.

Taylor, R.K., Schrock, M.D., Staggenborg, S.A., 2002: Extracting machinery management information from GPS data. ASAE Meet. Pap. 44(6): 1903-1911. https://doi. org/10.13031/2013.13933

Taylor, S.E., McDonald, T.P., Fulton, J.P., Corley, F., Brodbeck, C., 2006: Precision Forestry in the southeast US. $1^{\text {st }}$ Int. Precis. For. Symp. 397-414. 
Taylor, S.E., Veal, M.W., Grift, T.E., McDonald, T.P., Corley, F., 2002: Precision Forestry: operational tactics for today and tomorrow. $25^{\text {th }}$ Annu. Meet. Counc. For. Eng., 6 p.

Taylor, S.E., Veal, M.W., Mcdonald, T.P., Grift, T.E., 2001: Using GPS to evaluate productivity and performance of forest machine systems. Proc. First Int. Precis. For. Coop. Symp., $20 \mathrm{p}$.

Valbuena, R., Mauro, F., Rodriguez-Solano, R., Manzanera, J., 2010: Accuracy and precision of GPS receivers under forest canopies in a mountainous environment. Spanish J. Agric. Res. 8(4): 1047-1057.

Veal, M.W., Taylor, S.E., McDonald, T.P., McLemore, D.K., Dunn, M.R., 2001: Accuracy of tracking forest machines with
GPS. Am. Soc. Agric. Eng. 44(6): 1903-1911. https://doi. org/10.13031/2013.6978

Wang, J., Mcneel, J., Baumgras, J., 2001: A computer-based time study system for timber harvesting operations. For. Prod. J. 53(3): 47-53.

Wempe, M., Keefe, R.F., 2017: Characterizing Rigging Crew Proximity to Hazards on Cable Logging Operations Using GNSS-RF: Effect of GNSS Positioning Error on Worker Safety Status. Forests 8(10): 357. https://doi.org/10.3390/f8100357

Zimbelman, E.G., Keefe, R.F., Strand, E.K., Kolden, C.A., Wempe, A.M., 2017: Hazards in motion: Development of mobile geofences for use in logging safety. Sensors 17(4): 822. https://doi.org/10.3390/s17040822

(C) 2021 by the authors. Submitted for possible open access publication under the terms and conditions of the Creative Commons Attribution (CC BY) license (http://creativecommons.org/licenses/by/4.0/).

Raimondo Gallo, PhD

e-mail: raimondo.gallo@unibz.it

Free university of Bozen-Bolzano

Faculty of Science and Technology

Piazza universitá 1

39100, Bolzano

ITALY

Prof. Rien Visser, PhD *

e-mail: rien.visser@canterbury.ac.nz

Canterbury University

College of Engineering

School of Forestry

Private Bag 4800

Christchurch

NEW ZEALAND

Prof. Fabrizio Mazzetto, PhD

e-mail: fabrizio.mazzetto@unibz.it

Free university of Bozen-Bolzano

Faculty of Science and Technology

Piazza universitá 1

39100, Bolzano

ITALY

* Corresponding author 
